\title{
Home of the Humanistic Spirit of Painting - The pursuit of an art practitioner
}

\author{
Yao Luo ${ }^{1, *}$ \\ ${ }^{1}$ Jiangxi University of Science and Technology, Department of Humanities 156 Hakka Avenue, China
}

\begin{abstract}
The home of the humanistic spirit of painting is the author's self-soul question as an art practitioner, Also, the artistic pursuit of the spirit of reflection in the painting works in practice. This article discusses the idea that painting is the mother of language, and language is a rational symbol of painting, painting is the perceptual manifestation of ideas, and the root of Chinese painting is the humanistic spirit. It advocates the return of the humanistic spirit of Chinese painting., and taking Yao Luo's art as an example. It discusses that the artistic practice of the return of the humanistic spirit of painting, and propose the idea that artists can only create art that is needed by the times if they combine artistic practice with the inherent, and blend Chinese-Western culture with forward-looking humanistic spirit.
\end{abstract}

\section{Introduction}

Some people say that painting is just like music, some can feel it without saying a word. However, although painting has its own image language, painting is created by people. Language, on the other hand, is a bridge for human communication. As a creator of painting art, it cannot Lack of bridges for artistic communication. Throughout the development history of human culture and art, human beings have created language on the basis of painting, and the continuous enrichment and development of language has made painting glow with brilliant spiritual light. It can be said that the history of painting in the world is also a visible human being. The history of civilization is different from the development history of Western painting. Chinese painting has its own system, and the humanistic spirit is the most fundamental artistic brilliance of Chinese painting. The world today is undergoing great changes. In view of the copying, craftsmanship, and lack of humanistic spirit in contemporary Chinese painting, "the home of the humanistic spirit of painting" is Yao Luo's self-soul question as an art practitioner, and it is also In art practice, she pursues the artistic spirit of blending Chinese and Western.

\section{Painting is the mother of language, and language is the rational symbol of painting}

From the perspective of the development history of language, painting is the mother of language, language is the rational symbol of painting, language is the symbol of cultural communication full of human wisdom, and painting is the perceptual visual image that most touches the human soul. During the budding period, all languages in the world appeared in the form of carved symbols, rock paintings, and text paintings. On this basis, the simplified graphics produced the earliest phonographs of mankind. They are ancient Egyptian hieroglyphics, Chinese characters, and Mayan writing in the American continent are the only characters still in use and affecting Asia. Around 1300 BC, the Phoenicians developed the first batch of alphabets in human history based mainly on ancient Egyptian scripts. There were 22 letters in total. The Greeks reformed on the basis of the Phoenician alphabet and produced The writing order was changed to the Greek phonetic alphabet from left to right, and the Romans evolved the alphabet into the current Latin alphabet Roman alphabet around 700BC.Before the emergence of Chinese characters, "a picture opens the sky" was made into the "uncharacter book of heaven", that is, the Eight Diagrams map created by Fuxi to explain the mysteries of the universe. The Eight Diagrams map gradually developed into a unique Chinese hieroglyph, Chinese hieroglyphs Characters first appeared in the form of oracle bone inscriptions. Today, Chinese characters are also known as pictophonetic characters. It is simple to understand that the way that Chinese characters are made is related to images and sounds. They are language symbols formed on the basis of pictograms, understanding and referring to things. Gombrich mentioned in his book "The Story of Art" that the statues of early civilizations were not only related to spells and religions, but also the original form of writing. For example, ancient Mexican art extended the god snake rattlesnake as a sign of lightning.So it became a text symbol. From pictorial writing to today's alphabet and Asian characters, language gradually presents abstract and rational features due to the need for recording and dissemination. To

\footnotetext{
* Corresponding author: luohongni@ $126 . c 0 m$
} 
borrow Gombrich's words: "If we want to understand the story of art, then sometimes it is beneficial to think that painting and calligraphy are from the same source."[1] "Book" here refers to "language and writing", whether it is Chinese characters or letters, Is a kind of visual symbol. The difference is that Chinese characters have the characteristics of concrete and perceptual symbols, while the letters have the characteristics of abstract and rational symbols. Different language symbols form different cultural systems and have different characteristics. Cultural characteristics. Rigorous and scientific thinking is an important reason for the construction of a complete scientific system in the West. This scientific thinking has built a world-wide natural science system and has also promoted the continuous improvement of the world-wide social science system. There is a kind of imagery and sporadic Chinese thinking. Childlike innocence, Hegel believes that the world's "source of history is in China." "This stage can be roughly compared to childhood." "In Chinese religion and philosophy, people foresee a special prose style. Sense" [2] In Hegel's words, China is the childhood of world history. Like children, it has real interest and is as romantic and lyrical as prose. Hegel also believes that Chinese philosophy remains at an abstract level, but has transitioned to There is no logical order in concrete terms. As far as painting art is concerned, Western painting has the characteristics of science and rigor, which makes Western painting move from plane to three-dimensional, from concrete to abstract, from nature to soul, while Chinese painting has the characteristics of imagery and scatter, making Chinese painting always It has a lyrical, naive and romantic humanity.

\section{Painting is an artistic visual expression of the humanistic spirit}

Borrowing from Hegel's "idea", painting can be interpreted as: painting is an artistic visual expression of "idea", referring to all spirits that belong to the level of thought and soul. Hegel believes that the overall feature of art is beauty. In his "Aesthetics", the definition of beauty is: "True", "beauty is the perceptual manifestation of ideas." [3] Hegel's classic theory "Idea" is the ultimate meaning and highest form of beauty. At the same time, it points out the inherent contradiction of the concept of "idea", and finally ascribes all subjects and objects to his absolute spirit. Thus beauty, and therefore absolute spirit. [4] It can be understood that Hegel believes that "beauty" is "truth", and the way in which "idea" and "absolute spirit" are presented is art. Aesthetician Zhu Guangqian believes that "Hegel's definition affirms that art must have perceptual factors, and that art must have rational factors. The most important thing is that the two must form a seamless unity." [5] Hegel It is believed that the spirit will eventually withdraw from art and move towards a more advanced form that is more suitable for spiritual expression, namely religion and philosophy. That is, the "final conclusion of art" So, art has ended? In fact, regardless of East or West, "painting is still alive" has become an artistic phenomenon of "existence is reasonable". The author believes that the most attractive spirit of painting lies in the aesthetic value of at least two aspects. One is the beauty of distance, a distance that can never be reached. Painting has a distance that can always be seen, but reality can never be reached. It is distance, and art is convenient. With charm, the second is spiritual beauty. Painting is to construct a completely virtual artistic image on a completely empty two-dimensional plane. This virtual image presents the reality that you can see but never touch. What can be touched and felt may be the "idea" and "absolute spirit". Regarding Chinese painting, the "idea" can be explained as "humanistic spirit", and the concept is: "Chinese painting is an artistic visual expression of humanistic spirit."

\section{The essence of Chinese painting is the humanistic spirit}

Painting is an art form that Chinese people generally love and admire. The Chinese humanistic spirit has opened the door to Chinese painting and accompanied it all the way. The earliest visible scroll painting of characters in Chinese history, "Luo Shen Fu Tu", is related to Chinese literary genre $\mathrm{Ci}$ Fu. It was written by the painter and painter Gu Kai of the Eastern Jin Dynasty. His "Painting Yuntai Mountain" is also regarded as the pioneer of Chinese landscape painting. As a sign of the awakening of the art of painting, Gu Kaizhi's "Painting Theory", "Wei Jin Shengliu Painting Praise" and other painting theories, put forward major aesthetic propositions such as "writing gods in form" and "changing ideas to make wonderful achievements". Gu Kaizhi, known as "excellent painting, talent, and infatuation", opened the artistic road of Chinese figure painting and landscape painting. Tang Dynasty scholarofficial and poet Wang Wei started the journey of Chinese literati painting and became the originator of Chinese literati painting. Wang Wei (a poet, also known as Wang Youcheng) in a high position is also known as the ancestor of Chinese Nanzong ink landscape painting. There were many paintings in the Tang Dynasty that showed poetic sentiment and aesthetics. In the form of inscribed poems, the poems were written on the paintings. In the above, there is a poem by $\mathrm{Du} F u$ inscribed on the painting "The title of Wang Zai's painting of landscapes and songs" "Painting a water on ten days, and a mountain on five days, this matter is not subject to coercion, Wang Zai is willing to leave the original." [6] In the Northern Song Dynasty, Su Shi put forward the concept of "literati painting", opposed to the pursuit of complete similarity and advocated poetic and pictorial style of literati painting. In the Yuan Dynasty, Zhao Mengfu became the leader of literati painting and advocated "calligraphy and calligraphy of the same origin". In the Ming Dynasty, literati painting led the way and directly influenced In the Qing Dynasty, the basic pattern and aesthetic orientation of painting formed a painting system with Chinese national characteristics. Bada Shanren and Zheng Banqiao were outstanding representatives. Chinese "literati paintings" mostly 
express landscapes, flowers and birds, plums, orchids, bamboos and chrysanthemums, and pay special attention to the comprehensive presentation of poetry, calligraphy, and seals. The modern Chinese aesthetician and painter Luo Yiping uses the humanities such as "history and narration", "language and illustration", "good luck and heart source" in the three monographs of Chinese art history. A wonderful discussion on the spirit of art. History and works are telling posterity that the essence of Chinese painting is the humanistic spirit.

\section{The return of the humanistic spirit of Chinese painting is the need of art inheritance}

Chinese painting lacking the humanistic spirit will eventually lead to the loss and degradation of the artistic spirit. The return of the humanistic spirit of painting is Yao Luo's self-soul questioning as an art practitioner. It is the source of "not forgetting the original intention", and it is after the return. start again. Liu Yuedi believes that the evaluation of contemporary Chinese art must have at least double standards, one is "the originality of creativity" and the other is "the complex nature of meaning". Yao Luo believes that the "basic nature" can be interpreted as the artistic spirit of art practitioners. The fusion of the commonality of personality and traditional humanistic spirit, the "complexity of meaning" can be expanded into three dimensions: one is that practitioners should pay attention to the sublimation of the fundamental humanistic spirit, and the other is that practitioners should focus on Chinese and Western art The third is to focus on cross-border and cross-over collision. In the 20th century, Western art has undergone subversive development. Duchamp's anti-visual essence is anti-aesthetic and anti-representation. His anti-art strategy is based on traditional representation and aesthetic theory. [7] Duchamp's value is not so much to question the boundaries and essence of art, but rather to say that Western art has entered a new field of experimental art that is completely different from before. Since art experimentation is centered on anti-tradition and anti-aesthetics, then We need to reflect on a question. Does human civilization still need aesthetics? "History of European Painting" by Shao Dazhen and Xi Jingzhi analyzed the trends of modern art in Europe and America since the 1970s. They believed that a remarkable feature of the art phenomenon of postmodernism was "an attempt to break through the aesthetic category and break the boundaries between art and life." ", and put forward that postmodernist aesthetic propositions need to be considered and discussed, and pointed out that one-sided and extreme trends of thought have brought great negative effects on art. [8] There is no doubt that the pillars of "truth, goodness and beauty" without any human civilization will collapse, and Western art will eventually return to art and aesthetics from anti-art and anti-aesthetics. "Painting does not die" is obvious in China. However, once abandoning the keen perception and expression of the human spirit, blindly pursuing painting techniques will inevitably lead to the loss of artistic spirit. Once painting enters the "reverse" by abandoning the precious legacy left by its ancestors Art" may betray the original intention of art and cannot inherit the past and the future. The "home of the humanistic spirit of painting" in China is the need for art inheritance.

\section{China's "Home of the Humanistic Spirit of Painting" is the way for art practitioners to return together}

The artistic inheritance of China's "Home of the Humanistic Spirit of Painting" involves two aspects, one is inheritance and the other is development. The so-called "inheritance" is to deeply understand what the classics should not be discarded, whether it is skills or culture, once they neglect the construction, they may be lost or perished; and "development" is the last manifestation of inheritance, in the home of the humanistic spirit of Chinese painting On the road of the painting, the integration of Chinese and Western, learning and absorbing the humanistic and artistic spirit of the Western painting system is an important path for progress and progress. At the beginning of the twentieth century, Chinese painters had made achievements in the integration of Chinese and Western painting arts, such as $\mathrm{Xu}$ Beihong, Lin Fengmian, Wu Guanzhong, and others. The fusion practice of Chinese and Western painting and the artistic spirit sparks generated by cross-border integration can undoubtedly promote the history of world painting improvement. However, in recent decades, China has rarely seen young people who have made efforts and explorations in the integration of Chinese and Western painting. On the one hand, under the unique art examination mode in China, because the art examination items sketch, color, and sketch all come from the Western art system Art students lack the understanding of traditional Chinese painting; on the other hand, most of the unique art examination training in China has been controlled by the market. In order to profit, the training model has moved to the test-taking routine teaching model, and the art students can draw in accordance with the routine, and the same picture, Lack of originality and spiritual expression, and increasingly deviate from the direction of artistic pursuit; more importantly, the cultural score requirements of the art examination are far lower than the non-art examination scores, which may cause the new generation of art to be too "craftsman" and lack "talent" "The consequences, if the lack of humanistic spirit construction, will have devastating consequences for the next generation of artistic growth. Similarly, the growing art workers have the phenomenon of focusing on utility, lack of sincerity, and lack of spirit in painting skills. If they lack the originality and spiritual orientation of 
academic management and research spirit, they lack a deep understanding of Chinese and Western paintings. Expression, it is impossible to contribute talents to the development of Chinese painting, it is impossible to construct an artistic ecology that inherits the past, and it is impossible to contribute Chinese artistic power to the development of the history of world painting. China's "Home of the Humanistic Spirit of Painting" must first collide with the spiritual sparks in the exchange of humanistic spirits between China and the West. It requires art workers to have the knowledge and cultivation of Chinese and Western compatibility. Thirdly, they must also have the skill of expressing Chinese and Western painting techniques. Finally, We must dare to carry out personalized and innovative artistic practice that blends Chinese and Western art, and we must have the experimental spirit that failure is the mother of success. China's "home of the humanistic spirit of painting" lies in the home of every art practitioner and let every art Practicing individuals with independent and free artistic spirit belong to the "home" of the humanistic spirit of painting, which is the way to develop Chinese painting art.

\section{A Case of Art Practice of "The Home of the Humanistic Spirit of Painting"- -Taking Yao Luo's Art as an Example}

The homecoming of the humanistic spirit of painting is first reflected in the combination of "theory and practice" by art practitioners. If theories lacking artistic practice are just talkative, while artistic practice lacking theoretical spiritual guidance is empty and boring. Taking Yao Luo's art as an example, Yao Luo believes that artistic creation should learn the logic, integrity, and rigor of scientific thinking, and achieve in-depth, orderly, continuous, and integrated when creating artistic works. Yao Luo has created a series of paintings on the theme of "water" for nearly 20 years, and has persistently practiced painting art on the theme of "water". On the one hand, Yao Luo sorted out the humanistic spirit of "water", and explored the fields of philosophy, aesthetics, religion, history, and literature related to "water" in China and the West, striving to find "water" in crossborder and intersecting fields. Yao Luo believes that "water" is the matrix of world civilization and belief, and the source of enlightening human spirit; Yao Luo argued in related papers that the "water" spirit is the core cultural gene and national spirit of Chinese civilization It is an important part of the Chinese Yin-Yang and Five Elements theory, the main carrier of Taoism, the symbol of Confucian gentleman and the manifestation of time and change. The connotation of "water" is the core spiritual concept of Buddhist belief, and the Chinese "water" There is a channel for communication between spirit and Western civilization; on the other hand, Yao Luo gives different ecological spirits of water such as streams, clear springs, big rivers, lakes, and seas in his painting art practice, and the "liquid, gaseous and solid state of water" "The three forms are expressed one by one, which systematically and comprehensively express the different visual images of water and abstract. This kind of thinking benefits from the logical and systematic nature of science. In the painting technique, it is in progress. The practice of Western blending techniques intends to naturally combine Western oil painting's scientific color and shape with Chinese painting's pen and ink and image expression techniques. Yao Luo believes that the exploration and experimentation of the blending of Chinese and Western painting techniques needs to be expanded, which may improve the world of painting art. A fusion art ecology. Since 2003, Yao Luo has successively written and published papers such as "Let art build a beautiful spiritual home for people in the age of science and technology", "On the important position of aesthetic education in the construction of socialist spiritual civilization", "Art is the creation of wisdom", and published monographs. "Yao Luo Oil Painting Collection" emphasized in the papers and monographs that "With the continuous satisfaction of human material pursuits, the spirit of harmony with material has been neglected, and the loss of humanistic spirit has become a global problem." [9] " Artists should construct their own three-dimensional artistic life, from the picture to the soul. The world needs a Chinese artist who has a global vision and has not lost his cultural personality" [10]. Yao Luo strives to build an art channel that blends Chinese and Western cultures based on the fundamental humanistic spirit, creating sincere and spiritual art.

\section{A Case Study of Yao Luo's Art Practice-A Glimpse of the Series of Paintings on the "Water"}

Yao Luo believes that the exploration of painting art that blends Chinese and Western paintings includes $\mathrm{Xu}$ Beihong, Zhu Dequn, Zao Wou-ki, Wang Hongjian, etc. in terms of oil painting development, and Liu Jude and Du Dakai in Chinese painting. In the practice of artistic creation with the theme of "water", a large number of oil paintings and Chinese paintings that blended Chinese and Western were created respectively, striving to present a unique painting ecology of Chinese and Western blending. Yao Luo's blend of Chinese and Western refers to Chinese freehand painting using rice paper, ink, brush, etc., borrowing from Mr. Ye Lang's concise summary of the spirit of Chinese aesthetics the term "image", Chinese freehand painting focuses on "image", which can be explained It is a form between realism and abstraction, visually between "like" and not "like", pursuing the likeness of the gods, focusing on the expression of the spiritual world; "West" mainly refers to European and American paintings, here mainly refers to oil paintings. Regional dominance is the change of oil painting art in Italy, France, and the United States. In terms of oil painting form, it mainly refers to classical, impressionist, expressionism, abstraction, etc. Classicism focuses on the scientific view of realistic modeling such 
as perspective, anatomy, and number ratio. Impressionism pays attention to the natural science color view of optical color spectrum, expressionism pays attention to the expression of spirit, abstractism is the opposite of realism in painting expression; the integration of Chinese and Western refers to two aspects: one is technique, and the other is humanistic spirit. The "Water" theme painting is a series of paintings developed by Yao Luo around the substance and spirit of "Water". From small streams to clear springs, large rivers, lakes, and seas, different types of water are represented; from water to clouds, and snow-capped mountains, different forms of water are represented; different forms of water are represented from concrete water to abstract water; from Chinese water to The water of the world; the ultimate goal is to use the water of painting to express the humanistic spirit and the water of returning home. Picture 1: San Diego Bay Sketch (1)Shelter Island; Picture 2: San Diego Bay Sketch (2)Shelter Island; Picture 3: San Diego Beach Sketch (1)Black's Beach; Picture 4: San Diego, USA Beach sketches (2)-Solana Beach; Figures 1 to 4 show Yao Luo's sketches on the bays and beaches of San Diego in the United States. The cosmopolitan bay and beach sketches belong to Yao Luo's "water" theme painting art creation system. In the "sea" part, Figure 1 and Figure 2, Figure 3 and Figure 4 are paintings in the same place using oil paintings and Chinese paintings for sketching. Yao Luo believes that such an artistic expression method is necessary for the art experiment of the integration of Chinese and Western paintings. To improve the practice of sketching with the integration of Chinese and Western painting techniques, Yao Luo has visited San Diego beaches in the United States five times for sketching. Yao Luo's overseas sketches also include the Mediterranean coast of Turkey and Italy; rivers and lakes in Germany, Switzerland, France, etc.; and the ice of northern New Zealand. Lake, Christchurch beach; onsite sketching in Sydney, Australia, coastal cities of Melbourne, etc. Through the "water" Yao Luo wants to express his understanding of life, faith, and love with the fusion of Chinese and Western, just as Lao Tzu said, "Water is good for all things without fighting, and it is evil for everyone, so it is more than Tao". "Water" contains The mystery and spirit of "Tao" reflect the laws of the universe and the laws of life. "Tao" is indescribable. Why not use painting to take a look?

\section{Conclusion}

Painting is the mother of language and language has enriched the humanistic spirit of painting. Painting and language are the most brilliant spiritual wealth of human civilization. "The home of the humanistic spirit of painting" is Yao Luo's spiritual consciousness as a practitioner of painting art. Only by combining painting practice with the rooted, Chinese-
Western, and forward-looking humanistic spirit can it find its place in the art of painting.

\section{Figures}

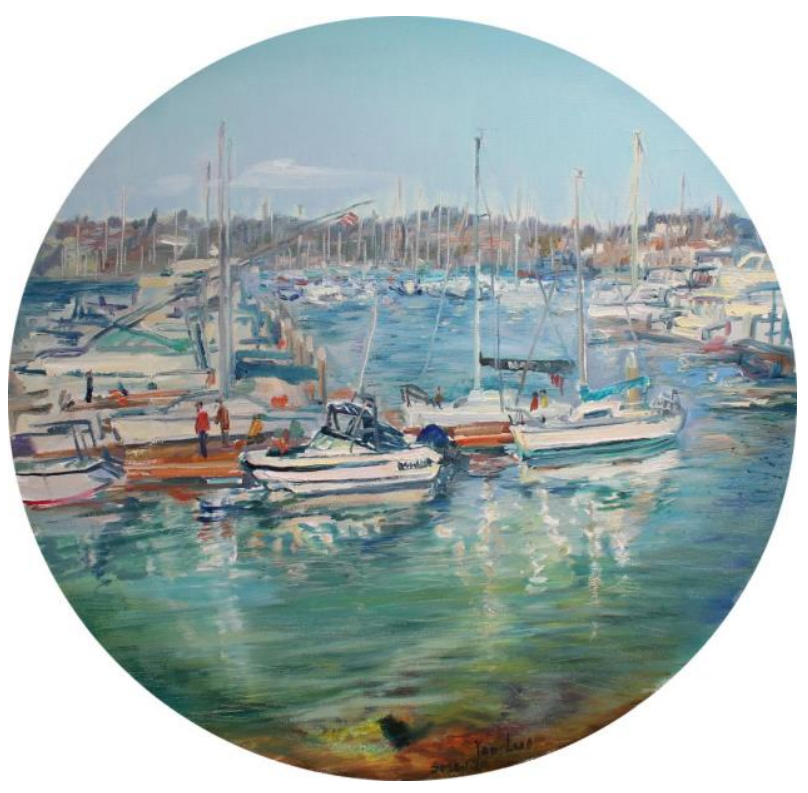

Fig.1.Sketch of San Diego Bay, USA (1)-Shelter Island Oil on canvas Specification:70cm diameter time 2020 Author: Yao Luo

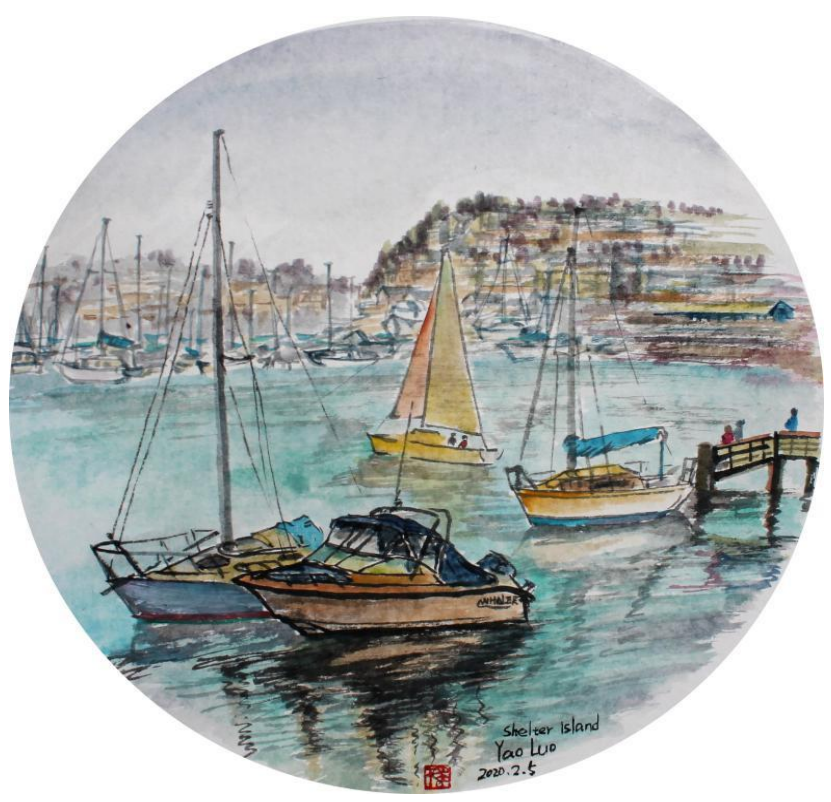

Fig.2. Sketch of San Diego Bay, USA (2)-Shelter Island Chinese painting on rice paper Specification: $38 \mathrm{~cm}$ diameter Time: 2020

Author: Yao Luo 


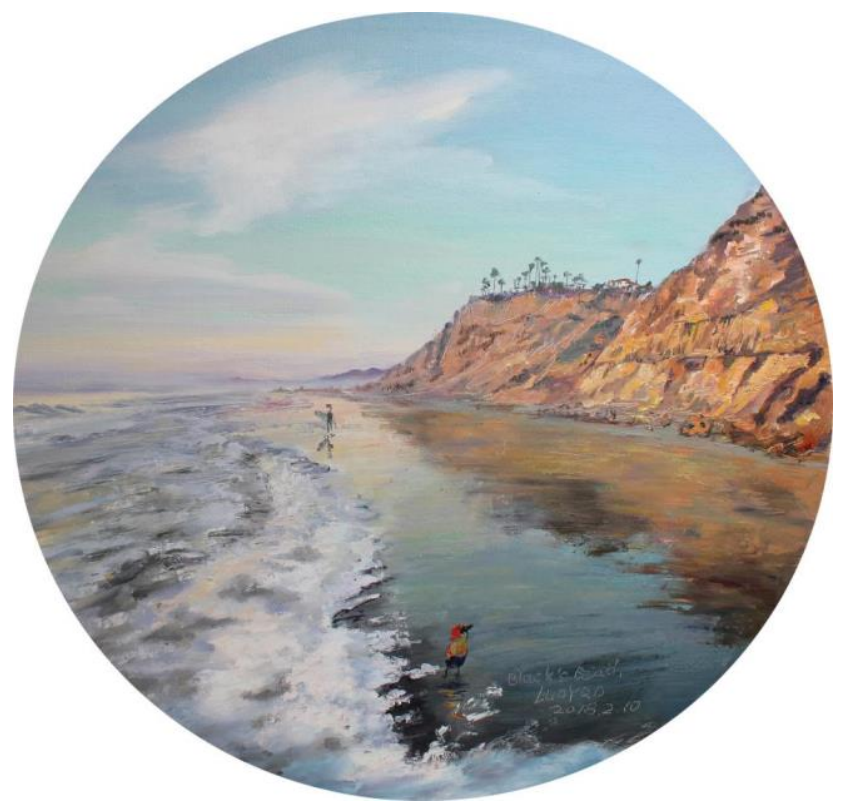

Fig.3. Sketch of San Diego Beach, USA (1)-Black Beach Oil on canvas Specification: 70cm diameter Date 2018 Author: Yao Luo

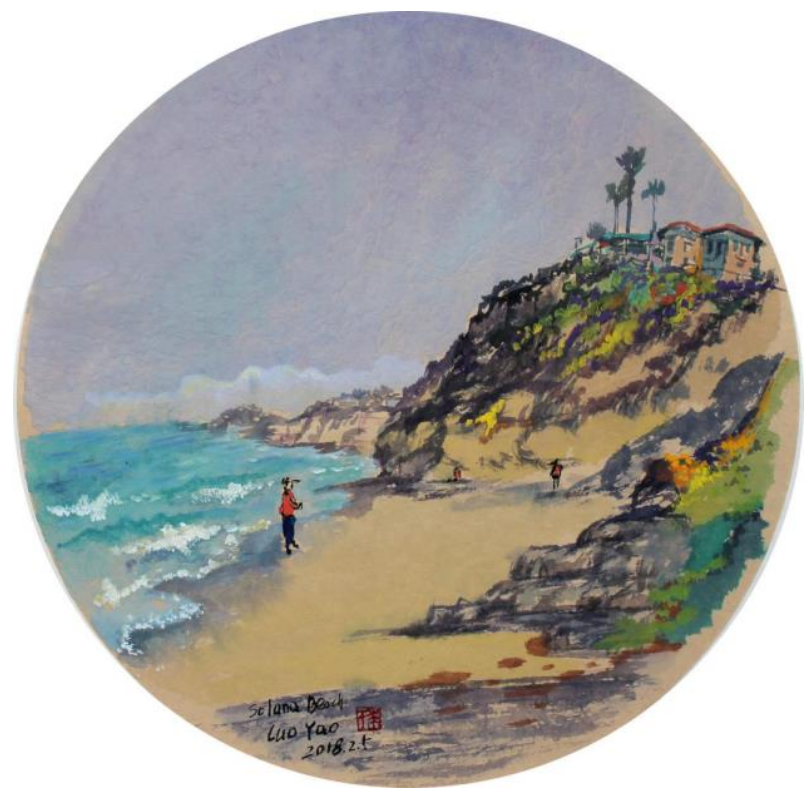

Fig.4. Sketch of San Diego Beach, USA (2)-Solana Beach Chinese painting on rice paper Specification: $38 \mathrm{~cm}$ diameter Time: 2018

Author: Yao Luo

\section{References}

1. E.H. Gombrich. The Story of Art $[\mathrm{M}]$ Nanning: Guangxi Fine Arts Publishing House, 2019: 50

2. Hegel,. Hegel's Philosophy of History [M] Beijing: Kyushu Publishing House. 2018:219.185.253
3. Hegel. Aesthetics: Volume 1 [M]. Beijing: The Commercial Press, 1981:142.

4. Feng Dong, Jiang Jiang, Ding Zhuo. From the Idea of Beauty to the Absolute Spirit-On Hegel's Aesthetic View [J] Journal of Northwest University (Philosophy and Social Sciences Edition) 2012(2):166

5. Zhu Guangqian. History of Western Aesthetics: Part Two [M]. Beijing: 1963: 478.

6. Pan Yungao, Yungao. Tang and Five Dynasties Painting Theory [M] Changsha: Hunan Fine Arts Publishing House. 2011:4

7. Zhang Bing. Theoretical Tendency and Diversified Patterns — - Perspecting Danto's View of the End of Art from the Perspective of Key Words [ J ] Theoretical Research of Literature and Art 2015 (5):116

8. Shao Dazhen. Xi Jingzhi. History of European Painting [ $\mathrm{M}]$ Shanghai: Shanghai People's Fine Arts Publishing House.2009:434-437

9. Yao Luo, Wang Jiafen. On the important position of aesthetic education in the construction of socialist spiritual civilization [J] 2004(12):99

10. Yao Luo. Art is the manifestation of wisdom [J] Feitian 2011 (11): 44 